\title{
MICRODISCHARGE-BASED PRESSURE SENSORS FOR OPERATION AT $1000^{\circ} \mathrm{C}$ Scott A. Wright ${ }^{*}$ and Yogesh B. Gianchandani \\ Engineering Research Center for Wireless Integrated MicroSystems (WIMS) \\ University of Michigan, Ann Arbor, MI, USA
}

\begin{abstract}
This paper reports microdischarge-based pressure sensors which operate by measuring the change in spatial current distribution of pulsed DC microdischarges. The sensors are composed of 3D arrays of horizontal bulk metal electrodes embedded in quartz substrates. Microdischarge-based pressure sensors are well-suited for high temperature operation because of the inherently high temperatures of the charged species that are generated. In this effort, temperatures of up to $1000^{\circ} \mathrm{C}$ are tested. The pressure sensors have a measurable pressure range of 10-760 Torr and require an active area of only $0.8 \mathrm{~mm}^{2}$. The sensor structures are designed to allow for unequal expansion of electrodes and substrate, during high temperature operation. The sensors demonstrate a maximum sensitivity of 5,000 ppm/Torr and temperature coefficients of sensitivity as low as $44 \mathrm{ppm} / \mathrm{K}$.
\end{abstract}

\section{INTRODUCTION}

Pressure sensors amenable to high temperatures have uses in numerous industrial segments including the combustion section of gas turbine engines, coal boilers, furnaces, and oil/gas exploration. A variety of microscale solutions have been explored. FabryPerot, and other interferometers, have been used on the ends of fiber optic cables and have been operated at temperatures of $800^{\circ} \mathrm{C}$ using sapphire membranes [1]. Bragg gratings have been photo inscribed into fibers and used to trace wavelength shifts caused by pressure changes at temperatures exceeding $350^{\circ} \mathrm{C}$, with the potential of operating at temperatures over $1,500^{\circ} \mathrm{C}$ [2]. High temperature piezoresisitve pressure sensors in silicon carbide [3], and more recently even in Si [4], are capable of operating at $600^{\circ} \mathrm{C}$; sensors operating at $800^{\circ} \mathrm{C}$ using sapphire membranes have also been developed [5].

Microdischarges are miniature plasmas created in gases between electrodes and are used for on-chip chemical sensing and other applications. Devices utilizing microdischarges are well suited for high temperature operation as the electrons have thermal energies exceeding $6.1 \mathrm{eV}(70,787 \mathrm{~K})$, and are not adversely affected by a high or low temperature ambient [6].

Microdischarge-based pressure sensors can be conceivably operated by measuring the change in spatial current distribution of microdischarges with pressure. As gas pressure increases, the mean free path of ionized molecules reduces and consequently, their spatial confinement changes. To measure the current distribution and microdischarge confinement, the microdischarges are created between a single anode and multiple cathode electrodes as shown in Fig. 1. The fractional current flowing through each cathode can be measured. At low pressures current favors the farthest cathodes while at high pressures, the opposite occurs. A repeatable relationship between current distribution and pressure allows such devices to be used as pressure sensors. A planar thinfilm version of the microdischarge-based pressure sensor was first reported in [7], and operated at temperatures up to $200^{\circ} \mathrm{C}$.

Microdischarge-based sensors are fundamentally different than ion gauges, which are not effective at atmospheric pressure because the small mean free path of the ions makes thermionic emissions difficult to detect [8].
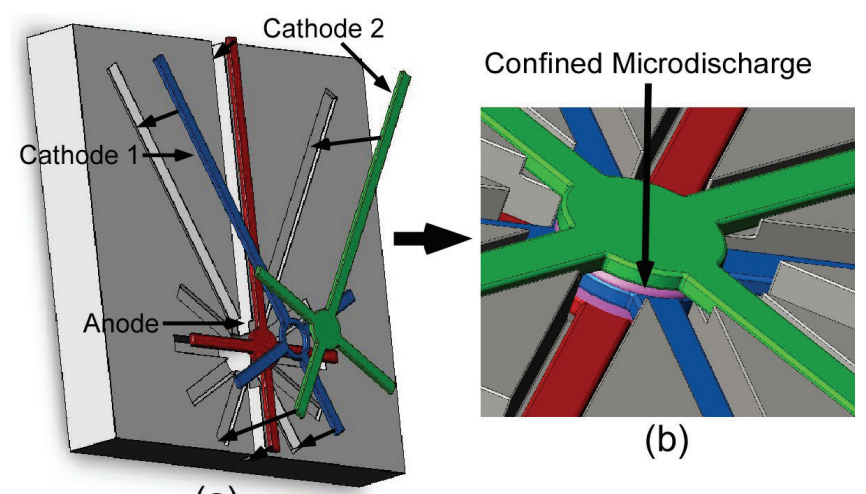

(b)

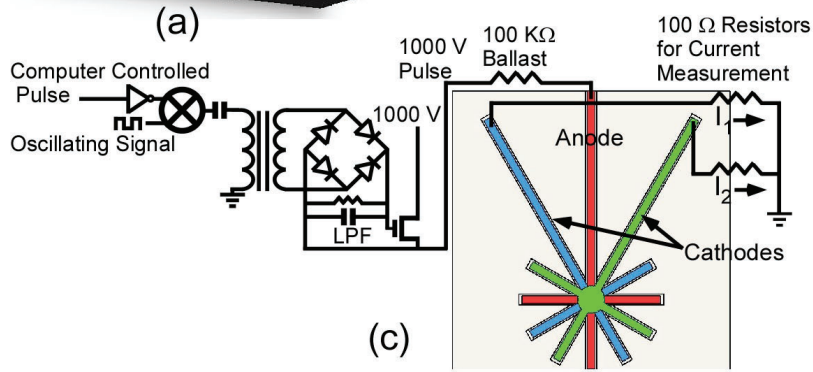

Fig. 1: Schematic of (a) electrodes above quartz chip illustrating placement, (b) microdischarge chamber during operation, and (c) isolation and readout circuitry.

This paper describes a new microdischarge-based microscale pressure sensor geometry that uses bulk foils in a multi-cathode stack in a quartz substrate. In this effort, we explore the use of multiple cathodes. In fact, multiple anodes may also be used. However, anode current shows excessive pressure dependence because of the high mobility of electrons that dominate it [9]. For this reason, measuring anode current results in pressure sensors with relatively small dynamic ranges.

\section{DEVICE DESIGN AND OPERATION}

The pressure sensor structure consists of several electrodes suspended over a cavity in a quartz chip. Each electrode has a single lead for electrical contact and between one and three additional supports, which maintain the suspended position of the electrode. A microdischarge chamber exists in the center of the chip, in a chip through-hole as shown in Fig. 1b. This chamber is formed by the sandwich of circular electrodes, in which microdischarges are created. A single disk-shaped anode electrode serves as the bottom of the chamber while the center electrodes are torus-shaped, allowing the discharges to exist between the bottom anode and all other electrodes. The top cathode is disk-shaped as well, confining the discharges.

To reduce power consumption and parasitic heating in the pressure sensors, pulsed DC microdischarges are used. At lower pressures ( $\approx<100$ Torr), a steady state DC current can be measured in the discharges, but as the pressure increases, thermal instabilities can occur which make DC measurements difficult. These plasma variations can be further influenced by electrode wear, re-

1301 Beal Ave., Ann Arbor, MI 48109, USA; Tel: (734) 763-6132, E-mail: scottwri@umich.edu 


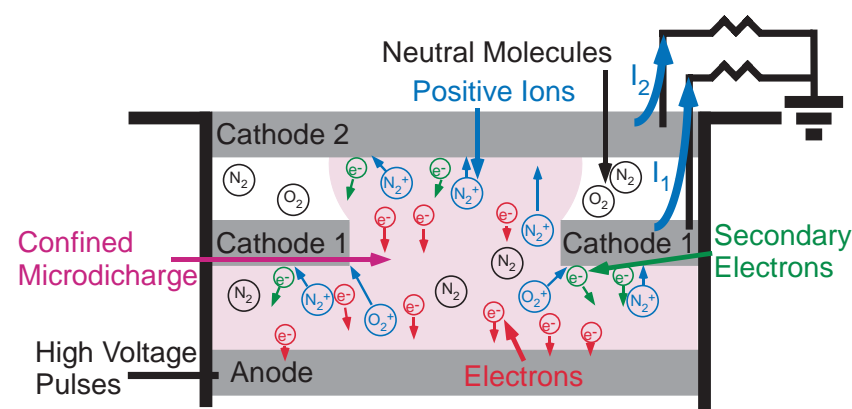

Fig. 2: Theoretical diagram of a microdischarge between a single anode and multiple cathodes in a microdischarge chamber. Changes in the ion distribution vary the currents in the cathodes.

deposition, and other factors. In our work, these issues are circumvented by using relatively short, pulsed DC microdischarges. A computer controlled, single ended, transformer coupled, gate drive circuit creates the pulses and is shown in Fig. 1c. A current limiting $100-\mathrm{k} \Omega$ ballast resistor is used, and $100-\Omega$ resistors are used in series with each cathode to measure current.

Figure 2 shows electron movement, ion movement, and current distribution in the microdischarges. The electrons are drawn towards the positive anode, creating positive ions from neutral molecules in the process which are drawn to the two separate cathodes. Based on the pressure, the fraction of the total ions reaching each cathode varies, which varies $\mathrm{I}_{1}$ and $\mathrm{I}_{2}$. Upon cathode impact, the energetic ions eject high energy secondary electrons from the cathodes, which sustain the DC microdischarges by ionizing additional neutral molecules and continuing the breakdown process. The current in each cathode is composed of the ions impacting the cathode and the secondary electrons leaving the cathode. While electrons carry most of the current in the plasma itself, they cannot reach the cathodes because of surrounding sheaths that are positively charged.

When designing the sensors, the spacing between the anode and the multiple cathodes is determined through theoretical calculations to allow for high sensitivity or a large dynamic range. The breakdown voltage between the anode and each cathode is a function of pressure $(p)$, spacing $(d)$, and density $(\rho)$ which is dependent on temperature and pressure. This breakdown voltage is used to estimate the threshold pressure, above which current deviates from a cathode further from the anode to one closer. The threshold pressure determines the dynamic range, as the sensors will not function effectively once current does not reach a cathode. The equation considering the dependence between breakdown voltage, pressure, spacing, and temperature is:

$$
V_{B}=B p\left(\frac{\rho}{\rho_{0}}\right) d\left[\ln \left[\frac{A p\left(\frac{\rho}{\rho_{0}}\right) d}{\ln (1 / \gamma)}\right]\right]^{-1}
$$

where in air the constant $A=15 \mathrm{~cm}^{-1}$ Torr $^{-1}, B=365 \mathrm{Vcm}^{-1}$ Torr $^{-1}$, and the secondary emission coefficient $\gamma=0.025$ for $\mathrm{N}_{2}^{+}$[10].

When designing the sensors to operate with a set operating voltage over pressure and temperature ranges of interest, the necessary electrode spacing can be calculated. Conversely for a set operating voltage and electrode spacing, the threshold pressure for cathode dominance, and dynamic range, can be found at different temperatures as illustrated in Table 1. As shown in the table, the dynamic range of the sensors increases with increasing
Table 1: Threshold pressure above which current deviates to closer cathodes for different anode/cathode spacing at various temperatures with $1000 \mathrm{~V}$ applied.

\begin{tabular}{|cc|c|c|c|c|}
\hline \multirow{2}{*}{$\begin{array}{c}\text { Cathode } \\
\text { Minimum spacing from } \\
\text { anode) }\end{array}$} & \multicolumn{4}{|c|}{$\begin{array}{c}\text { Estimated Pressure for Cathode } \\
\text { Dominance (Torr) }\end{array}$} \\
\cline { 3 - 6 } & $\mathbf{2 3}^{\mathbf{}} \mathbf{C}$ & $\mathbf{5 0 0}^{\mathbf{}} \mathbf{C}$ & $\mathbf{8 0 0}^{\mathbf{C}} \mathbf{C}$ & $\mathbf{1 0 0 0}^{\mathbf{}} \mathbf{C}$ \\
\hline 1 & $(225 \mu \mathrm{m})$ & 454 & 1185 & 1645 & 1951 \\
\hline 2 & $(300 \mu \mathrm{m})$ & 340 & 889 & 1233 & 1463 \\
\hline 3 & $(400 \mu \mathrm{m})$ & 255 & 666 & 925 & 1098 \\
\hline
\end{tabular}

temperature. This is because for a single cathode location, the threshold pressure increases with increasing temperature. However, the actual threshold pressures may differ from the predicted threshold pressures due to secondary electron emissions from the other cathodes, which continue to ionize surrounding gases. When operating within a sensor's dynamic range, changes in pressure will cause gradual fractional changes in current distribution between cathodes due to gradual changes in the mean free path, which affect the percentage of ions reaching each cathode.

The sensitivity and dynamic ranges are tuned by adjusting the number of electrodes, electrode thicknesses, inter-electrode spacing, and electrode diameter based on equation 1. A typical Three Cathode design with electrodes $50 \mu \mathrm{m}$ thick, $3 \mathrm{~mm}$ in diameter, and spaced $100 \mu \mathrm{m}$ apart is shown in Fig. 3a. These sensors have active areas of $7 \mathrm{~mm}^{2}$ and are fabricated on $4 \mathrm{~cm}^{2}$ chips. A typical Two Cathode design with electrodes $125 \mu \mathrm{m}$ thick, 1-2 mm in diameter, and spaced 50-100 $\mu \mathrm{m}$ apart is shown in Fig. 3b. These sensors have active areas of $0.8-3 \mathrm{~mm}^{2}$ and are fabricated on $1 \mathrm{~cm}^{2}$ chips. The Two Cathode design has electrode supports as well as electrical leads, to ensure horizontal orientation. The sensors are designed to function with an applied voltage of $1000 \mathrm{~V}$, but altering the voltage results in different sensitivities.
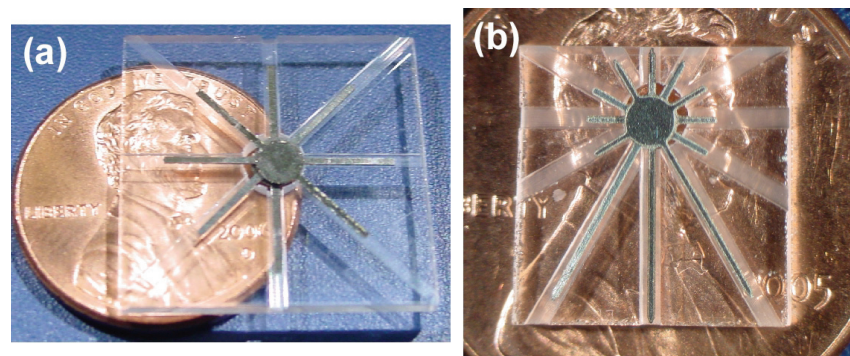

Fig. 3: Pressure sensors with (a) three cathodes and (b) two cathodes on pennies.

\section{FABRICATION}

A fabrication method that accommodates the expansion mismatch between electrodes and substrate is used (Fig. 4). The electrodes are lithographically patterned and etched from stainless steel, using chemical spray etching. Stainless steel is used for its robustness and oxidation resistance at high temperatures. Trenches of specified depths and a through-hole in the center are cut into a quartz chip. Both mechanical and wet-etch processes can be used for this purpose. The electrodes are assembled into the trenches, and the circular electrodes are placed in the through-hole. The different depths between the various trenches specify the discharge gap spacing, as the electrodes lie flush with the bottom of the trenches. Ceramic epoxy holds the electrode lead and support arms in place, without adhering to the stainless steel. This allows the leads and supports to expand separately from the quartz chip 


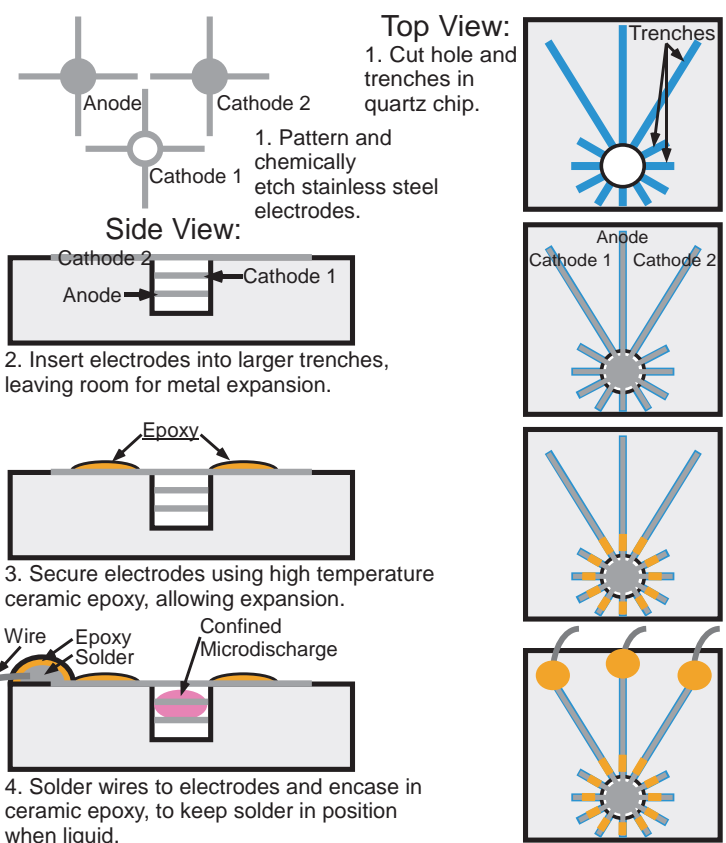

Fig. 4: Top and side view of a Two Cathode fabrication process.

and the ceramic epoxy without buckling. High temperature wires are soldered to the electrodes and the solder is encased in ceramic. This ceramic keeps the solder in position so it maintains electrical contact, even when the solder is liquefied at high temperatures.

\section{RESULTS AND DISCUSSION}

Individual pressure sensors were fabricated, operated, and characterized at temperatures between $23^{\circ} \mathrm{C}$ and $1000^{\circ} \mathrm{C}$, measuring pressures between 10 Torr and 760 Torr. Sensors were operated for over 10 hours at various temperatures to demonstrate durability. Pulses $1 \mathrm{~ms}$ in duration were applied at a rate of $40 \mathrm{~Hz}$ to the sensors with voltages between $700 \mathrm{~V}$ and $1000 \mathrm{~V}$. The pulses consumed between $168 \mu \mathrm{J}$ and $400 \mu \mathrm{J}$ each. The sensors were tested in a temperature controlled vacuum chamber.

Pressure was determined by measuring the percentage of total current in each cathode and calculating the differential current output between two cathodes. Figures 5 and 6 illustrate this, as

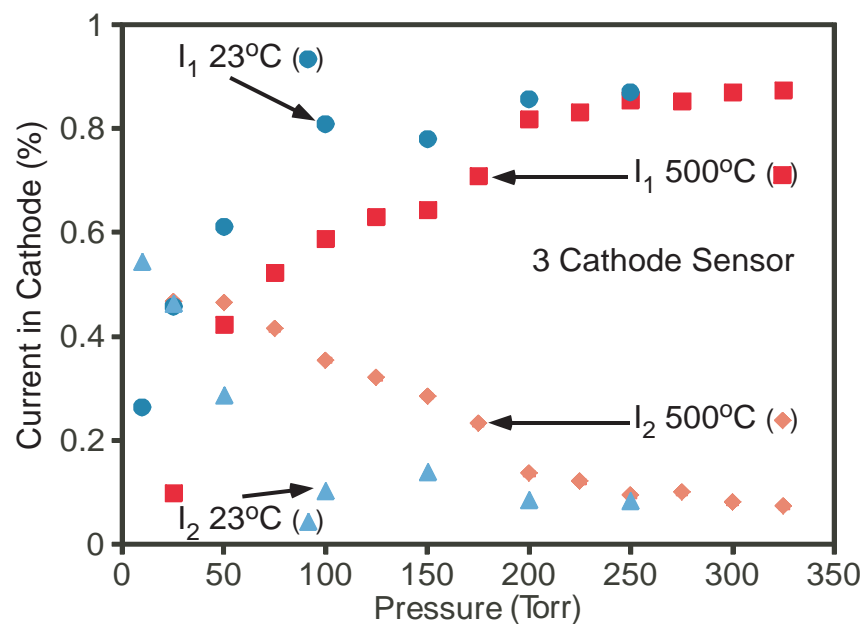

Fig. 5: Current distribution in a Three Cathode sensor. The sensor has electrodes $50 \mu \mathrm{m}$ thick, $3 \mathrm{~mm}$ in diameter, and spaced $100 \mu \mathrm{m}$ apart. Each data point is the average of 100 measurements.

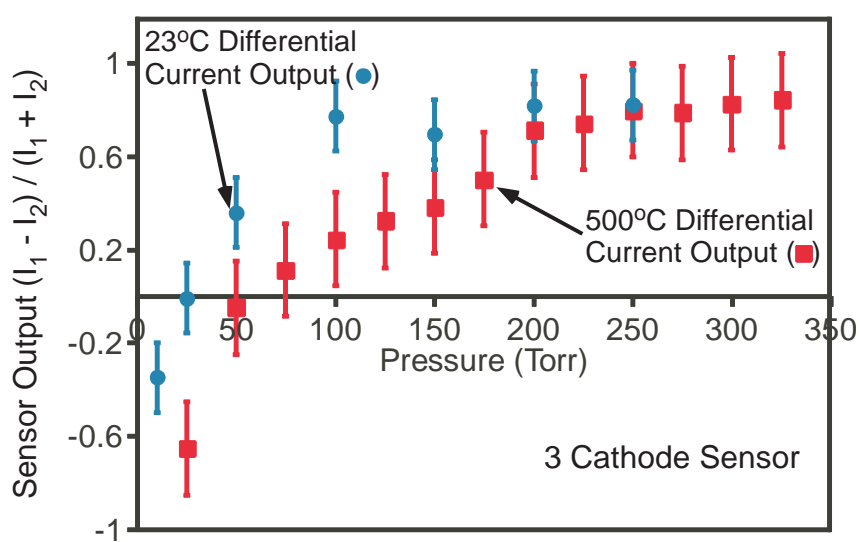

Fig. 6: Differential current output used to determine pressure from the current distribution in Fig. 5 at $23^{\circ} \mathrm{C}$ and $500^{\circ} \mathrm{C}$.

Fig. 5 presents the percentage of total current in two cathodes in a typical Three Cathode sensor at $23^{\circ} \mathrm{C}$ and $500^{\circ} \mathrm{C}$. (The third cathode only functioned to stabilize the microdischarges.) Figure 6 presents the differential current output calculated from the data in Fig. 5, used to determine the pressure. This sensor demonstrated relatively high sensitivities of 4,875 ppm/Torr and 4,979 ppm/Torr at $23^{\circ} \mathrm{C}$ and $500^{\circ} \mathrm{C}$ respectively, between 10 Torr and 300 Torr. It

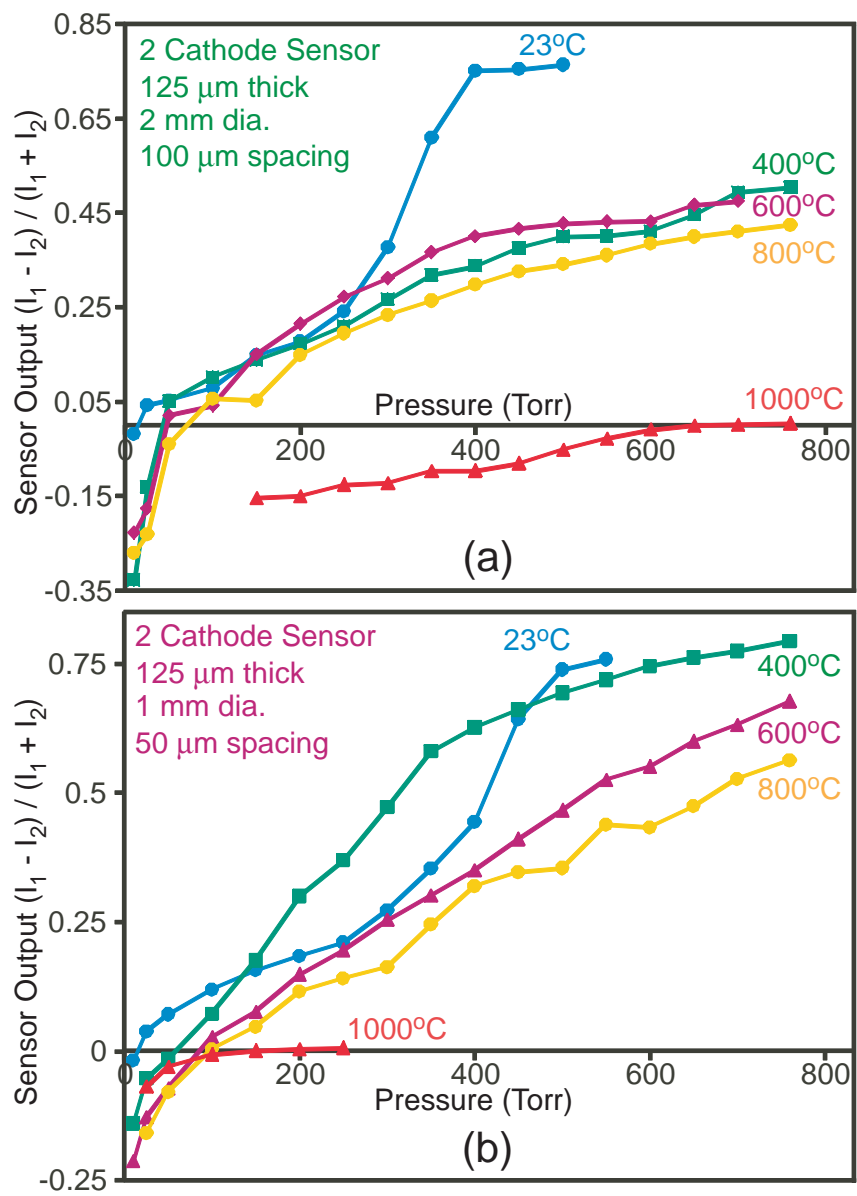

Fig. 7: Sensor output as a function of pressure in sensors with two cathodes and $125 \mu \mathrm{m}$ thick electrodes. (a) Output from a sensor with (a) $2 \mathrm{~mm}$ diameter electrodes spaced $100 \mu \mathrm{m}$ apart and (b) 1 $\mathrm{mm}$ diameter electrodes spaced $50 \mu \mathrm{m}$ apart. Each data point is the average of 100 measurements. 


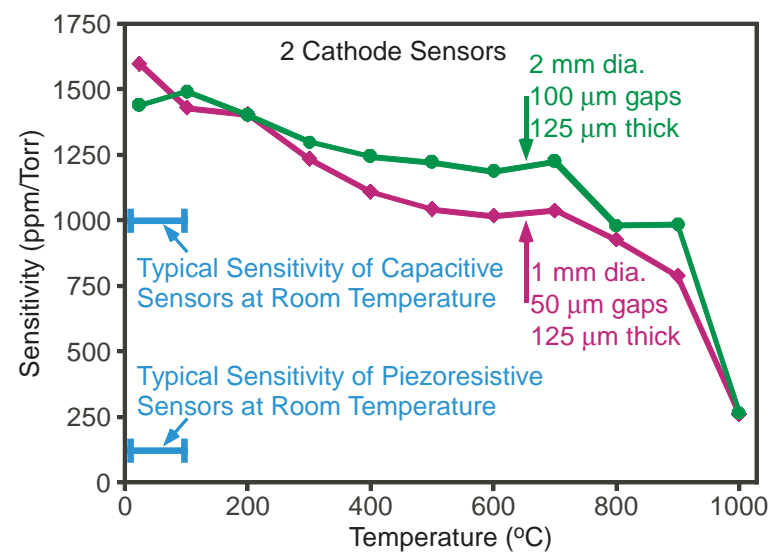

Fig. 8: The average sensitivities of the sensors in Fig. 7 as a function of temperature.

also had very little temperature dependence as shown by the 104 $\mathrm{ppm} /$ Torr sensitivity difference between $23^{\circ} \mathrm{C}$ and $500^{\circ} \mathrm{C}$.

The Two Cathode sensors were operated between $23^{\circ} \mathrm{C}$ and $1000^{\circ} \mathrm{C}$ over the pressure range of $10-760$ Torr. Figure 7 illustrates the differential current output used to determine pressure from two different, typical Two Cathode sensor designs. The first (Fig. 7a) is from a sensor with electrodes $125 \mu \mathrm{m}$ thick, $2 \mathrm{~mm}$ in diameter, and spaced $100 \mu \mathrm{m}$ apart while the second (Fig. 7b) is from a sensor with electrodes $125 \mu \mathrm{m}$ thick, $1 \mathrm{~mm}$ in diameter, and spaced $50 \mu \mathrm{m}$ apart. The average sensitivities of these two sensors are shown in Fig. 8 as a function of temperature. The sensitivities decreased with pressure, potentially as a result of the gas rarefaction, which occurred with increasing temperature. These sensors had smaller sensitivities but larger dynamic ranges than the previously described sensors (Figs. 5, 6) as shown by comparing the sensitivities in Figs. 6 and 8.

Sensitivity, dynamic range, and the temperature coefficient of sensitivity are metrics which are used to compare microdischargebased pressure sensor designs to one another and to other pressure sensors. The performance of four different sensor designs (data from one is not presented in this paper) are shown in Table 2 with the highest performance in each category. The data in the table represents typical operation of each sensor design. For comparison, typical piezoresistive and capacitive pressure sensors have sensitivities of $100 \mathrm{ppm} /$ Torr and 1,000 ppm/Torr respectively, and temperature coefficients of sensitivity of $\pm 1,000$ $\mathrm{ppm} / \mathrm{K}$ to $\pm 5,000 \mathrm{ppm} / \mathrm{K}[11,12]$.

\section{CONCLUSIONS}

Microdischarge-based pressure sensors have been developed and demonstrate an ability to operate from room temperature to $1000^{\circ} \mathrm{C}$ over the pressure range of $10-760$ Torr. These sensors can also potentially operate at temperatures below room temperature and over larger pressure ranges. The sensors currently occupy active areas as small as $0.8 \mathrm{~mm}^{2}$ on chips $1 \mathrm{~cm}^{2}$. They demonstrate sensitivities as high as 5,000 ppm/Torr and temperature coefficients of sensitivity as low as $44 \mathrm{ppm} / \mathrm{K}$. A new fabrication method is used which allows for expansion and contraction of electrodes with temperature variations, and may be of use in future high temperature microscale devices.

\section{ACKNOWLEDGMENTS}

The authors are grateful for the fabrication assistance received from Mr. M. Richardson. This work was supported primarily by
Table 2: Performance summary of four different sensor designs.

\begin{tabular}{|l|c|c|c|}
\hline $\begin{array}{l}\text { Sensor } \\
\text { Parameters }\end{array}$ & $\begin{array}{c}\text { Max } \\
\text { Sensitivity } \\
\text { (ppm/Torr) }\end{array}$ & $\begin{array}{c}\text { Dynamic } \\
\text { Range } \\
\text { (Torr) }\end{array}$ & $\begin{array}{c}\text { Temperature } \\
\text { Coefficient of } \\
\text { Sensitivity (ppm/K) }\end{array}$ \\
\hline $\begin{array}{l}\text { 2 cathodes } \\
\text { 2mm dia. } \\
100 \mu \text { m gaps }\end{array}$ & 1,500 & $\mathbf{7 5 0}$ & -857 \\
\hline $\begin{array}{l}\text { 2 cathodes } \\
\text { 1mm dia. } \\
50 \mu m \text { gaps }\end{array}$ & 1,500 & $\mathbf{7 5 0}$ & -912 \\
\hline $\begin{array}{l}\text { 2 cathodes } \\
\text { 1mm dia. } \\
100 \mu m \text { gaps }\end{array}$ & 2,000 & $\mathbf{7 5 0}$ & -1043 \\
\hline $\begin{array}{l}3 \text { cathodes } \\
\text { 3mm dia. } \\
100 \mu m \text { gaps }\end{array}$ & $\mathbf{5 , 0 0 0}$ & 300 & $\mathbf{4 4}$ \\
\hline
\end{tabular}

the Engineering Research Center Program of the National Science Foundation under Award No. EEC-9986866. Y. Gianchandani acknowledges support through the IR/D program while working at the National Science Foundation. The findings do not necessarily reflect the views of the NSF.

\section{REFERENCES}

[1] R. Fielder, K. Stingson-Bagby, M. Palmer, "State of the art in high-temperature fiber optic sensors,” SPIE, 5589(1), pp. 6069, 2004.

[2] T. Li, Z. Wang, Q. Wang, X. Wei, B. Xu, W. Hao, F. Meng, S. Dong, "High pressure and temperature sensing for the downhole applications," SPIE, 6757(1), pp. 1-7, 2007.

[3] A. Ned, R. Okojie, A. Kurtz, "6H-SiC pressure sensor operation at $600^{\circ} \mathrm{C}$," HITEC, Albuquerque, NM, pp. 257-260, 1998.

[4] S. Guo, H. Eriksen, K. Childress, A. Fink, M. Hoffman, “High temperature high accuracy piezoresistive pressure sensor based on smart-cut SOI,” MEMS, Tucson, AR, pp. 892-895, 2008.

[5] S. Fricke, A. Friedberg, T. Ziemann, E. Rose, G. Muller, D. Telitschkin, S. Ziegenhagen, H. Seidel, U. Schmidt, "High temperature $\left(800^{\circ} \mathrm{C}\right)$ MEMS pressure sensor development including reusable packaging for rocket engine applications," MNT for Aerospace Applications, CANEUS, pp. 5p, 2006.

[6] M. Kushner, "Modeling of microdischarge devices: Plasma and gas dynamics,” J. Phys. D: App. Phys., 38(11), pp. 16331643, 2005.

[7] S. Wright, Y. Gianchandani, "A harsh environment, multiplasma microsystem with pressure sensor, gas purifier, and chemical detector, MEMS, Kobe, Japan, pp. 754-757, 2007.

[8] C. Edelmann, "Measurement of high pressures in the vacuum range with the help of hot filament ionization gauges," Vacuum, 41(7-9), pp. 2006-2008, 1990.

[9] C. Wilson, Y. Gianchandani, R. Arslanbekov, V. Kolobov, A. Wendt, "Profiling and modeling of dc nitrogen microplasmas," J. Appl. Phys., 94(5), pp. 2845-2851, 2003.

[10]J. Cobine, Gaseous Conductors Theory and Engineering Applications, New York, Dover Publications, 1958.

[11]Y. Zhang, K. Wise, "Performance of nonplanar silicon diaphragms under large deflections,” J. Microelectromech.Sys., 3(2) pp. 59-68, 1994.

[12]M. Gad-el-Hak, The MEMS Handbook, Second Edition, Boca Raton, FL, CRC Press, 2006. 